\title{
Comparison of Antiretroviral Therapy Adherence Among HIV-Infected Older Adults with Younger Adults in Africa: Systematic Review and Meta-analysis
}

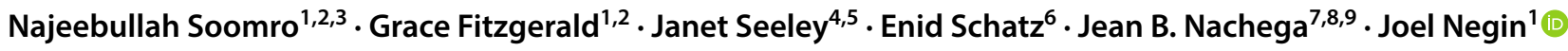

Published online: 3 July 2018

(c) The Author(s) 2018

\begin{abstract}
As access to antiretroviral treatment in low- and middle-income countries improves, the number of older adults (aged $\geq 50$ years) living with HIV is increasing. This study compares the adherence to antiretroviral treatment among older adults to that of younger adults living in Africa. We searched PubMed, Medline, Cochrane CENTRAL, CINAHL, Google Scholar and EMBASE for keywords (HIV, ART, compliance, adherence, age, Africa) on publications from 1st Jan 2000 to 1st March 2016. Eligible studies were pooled for meta-analysis using a random-effects model, with the odds ratio as the primary outcome. Twenty studies were included, among them were five randomised trials and five cohort studies. Overall, we pooled data for 148,819 individuals in two groups (older and younger adults) and found no significant difference in adherence between them [odds ratio (OR) 1.01; 95\% CI 0.94-1.09]. Subgroup analyses of studies using medication possession ratio and clinician counts to measure adherence revealed higher proportions of older adults were adherent to medication regimens compared with younger adults (OR 1.06; 95\% CI 1.02-1.11). Antiretroviral treatment adherence levels among older and younger adults in Africa are comparable. Further research is required to identify specific barriers to adherence in the aging HIV affected population in Africa which will help in development of interventions to improve their clinical outcomes and quality of life.
\end{abstract}

Keywords HIV $\cdot$ Adherence $\cdot$ ART $\cdot$ Africa $\cdot$ Older adults $\cdot$ Systematic review

\section{Introduction}

Globally, there are 36.7 million people living with human immunodeficiency virus (HIV), of which $69 \%$ live in Africa [1]. UNAIDS estimated that in 2016 there were 5.8 (5.3-6.2) million people aged 50 years and older living with HIV, representing $17 \%$ of all adults aged 15 years and over living

Joel Negin

joel.negin@sydney.edu.au

1 Sydney School of Public Health, The University of Sydney, Edward Ford Building (A27), Sydney, NSW 2006, Australia

2 Rural Health Mildura, Monash University, Victoria 3500, Australia

3 Broken Hill University Department of Rural Health, The University of Sydney, Broken Hill, Australia

4 London School of Hygiene \& Tropical Medicine, London, UK

5 MRC/UVRI Uganda Research Unit, Entebbe, Uganda with HIV [2]. Their modelling data also predicts that the number of older adults living with HIV in low- and middleincome countries around the world will increase by $47 \%$ by 2020 and most of them will be living in sub-Saharan Africa (SSA).

Over the past decade there has been an increase in the access to life-prolonging antiretroviral therapy (ART),

6 School of Health Professions, University of Missouri, Columbia, USA

7 Department of Medicine and Centre for Infectious Diseases, Stellenbosch University Faculty of Medicine and Health Sciences, Cape Town, South Africa

8 Departments of Epidemiology, Infectious Diseases and Microbiology, University of Pittsburgh Graduate School of Public Health, Pittsburgh, PA, USA

9 Departments of Epidemiology and International Health, Johns Hopkins Bloomberg School of Public Health, Baltimore, MD, USA 
and factors such as improved HIV surveillance, clinician awareness of HIV, advancement of diagnostic techniques etc., have led to an increase in people aged 50 years and older living with HIV [3, 4]. As life expectancy in Africa is lower than developed countries around the world, WHO projects in Africa have categorized older adults as people aged 50 years and older [5]. This definition of older adults for reporting HIV incidence and ART adherence, in low and middle income countries, is well documented in the in published literature [6, 7].

With the increased life span, ageing population is becoming susceptible to other causes of ill health $[8,9]$, which in turn may affect their adherence to ART. Evidence shows that poor immunological response to ART is a surrogate of biological ageing [10]. The natural ageing process causes a decline in immunocompetence making older adults susceptible to both communicable and non-communicable diseases such as diabetes and hypertension when compared to young adults [11-13]. Therefore, understanding adherence of older adults to ART is paramount to develop strong HIV treatment programs.

Optimal adherence has both individual health benefits as well as wider public health benefits such as prevention of HIV endemic and improvement of mental health $[14,15]$. Whereas poor adherence leads to incomplete viral suppression allowing disease progression which ultimately increases mortality [16, 17]. In 2014, UNAIDS called for the ambitious 90-90-90 targets with the aim of ending the global AIDS epidemic by improving surveillance, ART adherence and viral suppression in infected individual [18]. The program was aimed to achieve its goals by 2020 and one of the targets was to have $90 \%$ of all people receiving anti-retroviral treatment (ART) achieve viral suppression by 2020 . This target can only be achieved if there is a strong emphasis on ART adherence. Despite the growing recognition that older people are increasingly infected with HIV $[6,19]$ and are accessing treatment, the literature on ART adherence among older adults is limited [20,21]. This is particularly true in SSA where the burden of HIV among older adults is highest, and treatment and adherence challenges are greatest due to overburdened health services that are not set up to address older peoples' needs.

A recent review has shown that the adherence to ART among older adults is higher than that of younger adults in developed countries [7]. There are reasons to believe this in the context developed countries, where older adults are likely to be financially stable and medically aware about their health. However, older adults in SSA might experience different barriers to adherence when compared to younger adults. These might include high rates of poverty, limiting money for transport and care [22, 23]; multi-morbidity with various chronic diseases leading to poly-pharmacy [24]; social isolation [25]; ageism or elder abuse [22]; and little understanding among health providers of older persons' needs [22, 24]. Another important determinant of adherence in elderly is neurocognitive impairment. It has been shown that decline in executive functioning, motor functioning, and processing speed leads to suboptimal adherence in older adults [26]. Moreover, in high morbidity/mortality and high poverty areas, older adults often lose their caregivers and must provide care to others while suffering from age-related illness and frailty [27, 28]. As a result they may feel lonely, disconnected and despondent eventually becoming hopeless and demotivated to seek treatment [29,30]. Depression is a surrogate of this sequel which has been shown to be a predictor for non-adherence (OR 2.54; 95\% CI 1.65-3.91) [31].

A critical first step to improving adherence among older adults in Africa and thus helping to achieve the 90-90-90 targets is to understand current levels of treatment adherence. Currently there is no synthesis in the literature on the comparison of adherence rates for ART between older and younger adults living in Africa. Therefore, we conducted a systematic review and meta-analysis to examine adherence to ART in Africa among older adults compared to younger adults.

\section{Methods}

\section{Definitions}

For the purposes of this systematic review, we defined ART as any combination of antiretroviral therapy. Adherence pertains to the correspondence between a patient's actual medication use and the regimen prescribed by a health care provider [32]. Adherence measurement may include the use of subjective measures i.e. self-reporting or objective measures such as pill-counts or medication possession ratio (MPR) [33]. Self-reporting by the use of any survey instrument was acceptable, including AIDS Clinical Trial Group (ACTG) adherence questionnaire [34]. The MPR was defined as the proportion of prescribed days' supply obtained from the pharmacy during a specified observation period-generally the refill interval for a given prescription [35]. Older adults were defined as anyone aged 50 years and above. Individuals aged between 15 and 50 were categorized as young adults.

\section{Search Strategy and Selection Criteria}

The study follows the PRISMA (Preferred Reporting Items for Systematic Reviews and Meta-Analyses) guidelines for search strategy, which aims to locate all published articles on the topic. The databases identified for this review were PubMed, Medline, Cochrane CENTRAL, CINAHL, Google scholar, and EMBASE, plus reference lists of relevant articles. The databases searched were based on the keywords: 
human immunodeficiency virus, antiretroviral therap*, compliance OR adherence, age* (elderly/older adults/adults), Africa. The search included all articles published from 1st Jan 2000 to 1st March 2016.

\section{Inclusion Criteria}

The review considered studies that included people on ART, included data on participants aged 50 years and above and compared them to a younger cohort, that were conducted in Africa and that included data on adherence. We included cross-sectional studies, prospective studies, retrospective studies, case control studies and randomized control trials. We considered studies that covered data on adherence to ART using a wide variety of measures. We excluded case reports, reviews and publications in languages other than English.

\section{Data Extraction and Analysis}

The study-screening process adhered to PRISMA recommendations. After duplicates were removed from the independent searches, articles were excluded per the identified criteria for study selection. It is illustrated in Fig. 1.

Where a screened study made reference to adherence but did not present data on adherence rates in that cohort, author GF contacted the corresponding author to ask if appropriate data were available. Similarly, if a study presented adherence rates that were not stratified into age groups, author GF
Fig. 1 Prisma flow chart of study selection process. *Where articles only included children or did not include older adults
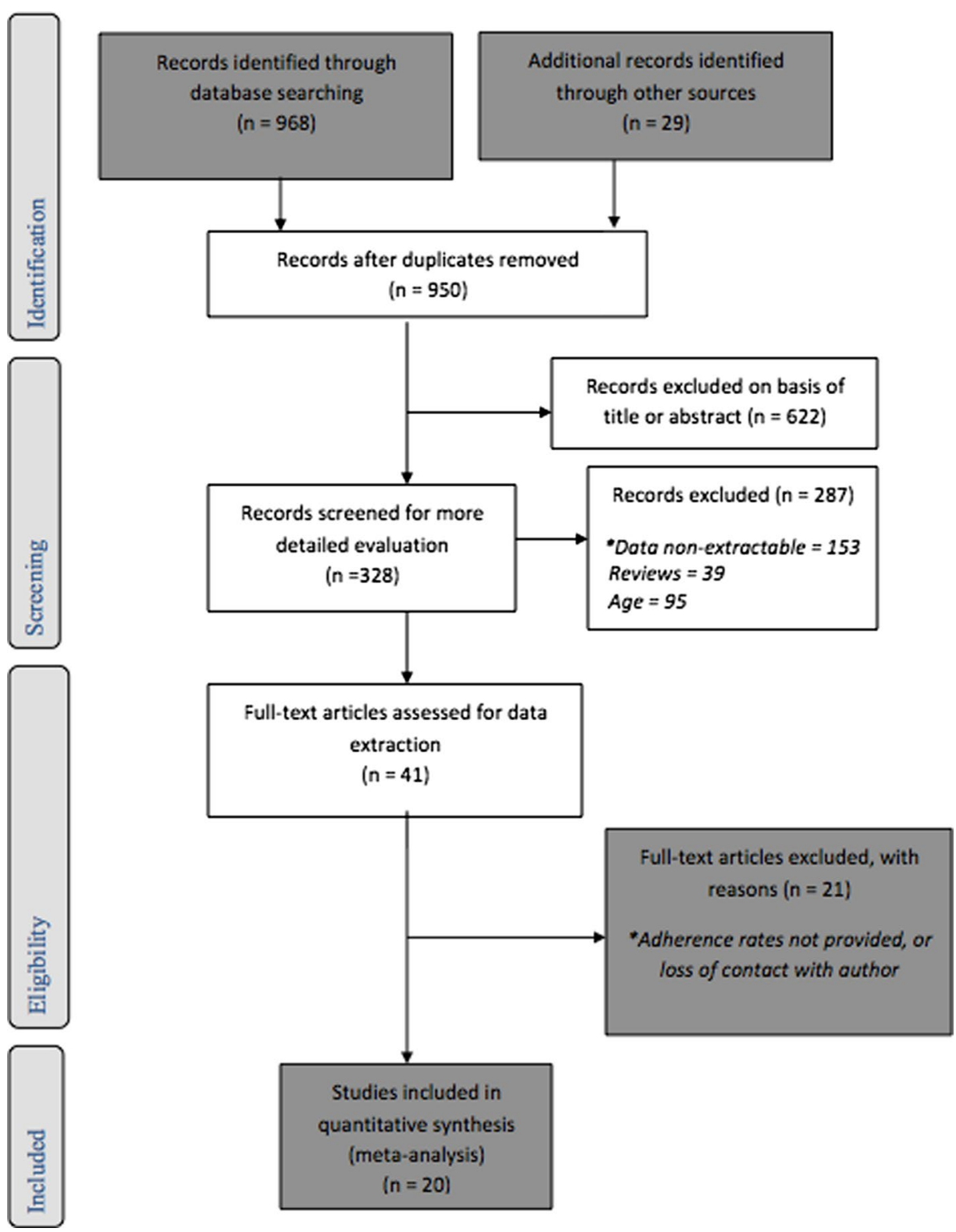
contacted the author to assess the possibility of stratifying the relevant data.

\section{Data Extraction}

Quantitative data was extracted by NS and GF using the standardized data extraction tool from JBI-MAStARI [36] (Appendix 1). Information was extracted pertaining to study title, author names, and publication year, research design, and adherence measures. Sample data relating to number of participants, follow up periods and number of participants (total and in both the older and younger age groups) was collected. The outcome measures extracted were the proportion of adherence in the older and younger age groups, recorded as number of adherent participants in each group, and proportion of that group who were adherent.

\section{Assessment of Methodological Quality}

Given the use of both randomized and non-randomized studies in our analysis, methodological quality was assessed using a modified version of the Downs and Black Framework [37]. Studies were independently scored using 24 quality criteria. As most studies included in the analysis were either cohort studies or cross-sectional studies, questions pertaining to Randomization or RCTs were excluded (Appendix 1 describes the items and their assessment). With the exception of one item scored from 0 to 2 points, all items were scored as follows: $1=$ yes ( 1 point $),-=$ no $(0$ points $)$, $?=$ don't know (0 points).

\section{Meta-analysis}

We pooled studies using Comprehensive Meta-Analysis software v 3.3.070 (2014). All results were subjected to double data entry check. The odds ratio (OR) for each study was calculated and we used a random-effects (DerSimonian-Laird) approach for pooling. We examined heterogeneity using the $\mathrm{I}^{2}$ value. We first pooled all randomized trials and then added observational studies. We examined differences in treatment effects according to study designs.

\section{Results}

\section{Study Characteristics}

From 968 studies initially identified, 328 were screened for detailed evaluation. Between August and November 2016, 169 authors were contacted, and 22 of those responded to provide further information. Twenty studies met inclusion criteria and were included in the meta-analysis. Figure 1 presents the search results and the number of studies extracted from research databases. The 20 studies identified for inclusion included eight cohort studies, two retrospective cohort studies, five cross-sectional studies, four randomized trials, and one case-control study. In terms of geographical area six studies used data from Zambia, three from Cote D'Ivoire, two each from Uganda, Tanzania, Kenya, and South Africa. Table 1 depicts the characteristics of the included studies.

Table 2 describes different adherence measures used in the included studies. Adherence was most commonly measured by patient self-reported questionnaires, or by pill counts systems. Two studies calculated MPR, and another two constructed an adherence measure based on clinical contact. The most frequent definition of adherence was equal or greater than $95 \%$ compliance with the prescribed regime of ART.

\section{Quality Assessment}

Individual study scores are summarized in Appendix 2. Studies were considered "high quality" if they scored $60 \%$ of the maximum score.

\section{Meta-analysis}

The overall cohort of subjects for the 20 included studies was 148,819 . The pooled data showed that of the 12,401 older adults, $8947(72.15 \%)$ were considered adherent; and of the 136,351 young adults, $92,705(68.03 \%)$ were adherent. The meta-analysis yielded a pooled OR of 1.01 (95\% CI 0.93-1.09), showing no difference in the likelihood of adherence between older and younger adults $\mathrm{p}=0.85$ (Fig. 2).

Due to the heterogeneity of methods used for measuring adherence, a sub-group analysis was conducted by grouping subsets of studies that used similar methodology for measuring adherence. Four studies used MPR and clinician counts, six used pill counts and seven used self-reports for measuring adherence. When pooled by objective measures of adherence monitoring i.e. MPR and clinician counts, the analysis showed significantly higher proportions of adherence among older adults compared with their younger peers OR 1.06 (95\% CI 1.02-1.11). However, when data from the six studies using objective measure of pill counts was pooled, there was no difference between the two groups OR 0.84 (95\% CI 0.65-1.09). Meanwhile pooling of studies using subjective measure of adherence 'self-report' showed no significant difference between the older and younger cohorts OR 0.92 (95\% CI 0.72-1.18). Additional sub-group analyses can be found in Appendix 3 (Fig. 3).

A further analysis on the effect of study design was carried out. The studies were sub-divided into four groups, RCTs (4), cross-sectional studies (5), prospective cohort studies (7) and others (retrospective cohort, case-control, etc.) (3). When the data from the four RCTs was analysed as a group, the results showed no statistically 


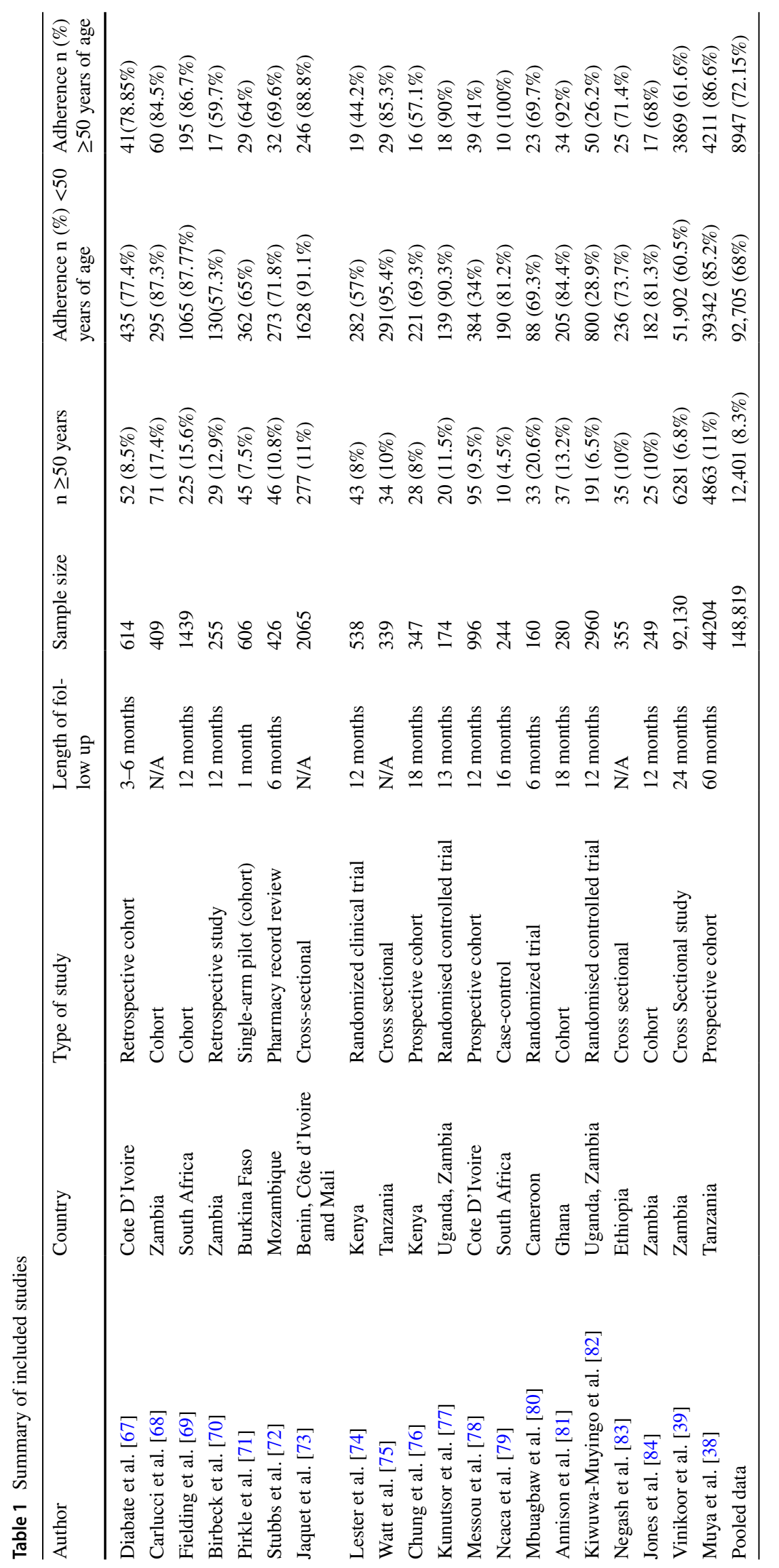


Table 2 Summary of adherence measures

\begin{tabular}{|c|c|c|}
\hline Author & Adherence measure & Adherence cut off \\
\hline Diabate et al. [67] & Self report with $\mathrm{ACTG}^{\mathrm{a}}$ & $\geq 95 \%$ \\
\hline Carlucci et al. [68] & Pill count & $\geq 95 \%$ \\
\hline Fielding et al. [69] & Self report & $100 \%$ reported adherence in last 3 days \\
\hline Birbeck et al. [70] & Attendance at clinic and self report & $\begin{array}{l}\text { Attended all scheduled ART clinic visits } \\
\text { with no lapse in drug collection and } \\
\text { documentation }\end{array}$ \\
\hline Pirkle et al. [71] & Self-report & N/A \\
\hline Stubbs et al. [72] & Pill count & $\geq 90 \%$ \\
\hline Jaquet et al. [73] & Self report with $\mathrm{ACTG}^{\mathrm{a}}$ & $\geq 95 \%$ \\
\hline Lester et al. [74] & Self report—asked how many pills missed in 30 days & $\geq 95 \%$ \\
\hline Watt et al. [75] & Self report with $\mathrm{ACTG}^{\mathrm{a}}$ & $\geq 95 \%$ \\
\hline Chung et al. [76] & Pill count & $\geq 95 \%$ \\
\hline Kunutsor et al. [77] & Pill count & $\geq 95 \%$ \\
\hline Messou et al. [78] & Pill count & $\geq 95 \%$ \\
\hline Ncaca et al. [79] & Medication possession ratio & $\geq 95 \%$ \\
\hline Mbuagbaw et al. [80] & Self report using visual analogue scale & $\geq 95 \%$ \\
\hline Annison et al. [81] & Self report & Patients without treatment interruptions \\
\hline Kiwuwa-Muyingo et al. [82] & Pill count and structured questionnaire & $\begin{array}{l}\text { Good adherence defined as "did not miss } \\
\text { a dose in last month" }\end{array}$ \\
\hline Negash et al. [83] & $\begin{array}{l}\text { Self report of medication doses taken divided by medication } \\
\text { doses prescribed }\end{array}$ & $\geq 95 \%$ \\
\hline Jones et al. [84] & Self report using $\mathrm{ACTG}^{\mathrm{a}}$ & Adherence over last two weeks \\
\hline Vinikoor et al. [39] & Medication Possession ratio & $\geq 95 \%$ \\
\hline Muya et al. [38] & Compliance with pick-up visits & $\geq 95 \%$ \\
\hline
\end{tabular}

${ }^{a}$ AIDS Clinical Trial Group Adherence Questionnaire [34]

\begin{tabular}{|c|c|c|c|c|c|c|c|c|}
\hline \multirow[t]{2}{*}{ Study name } & \multicolumn{5}{|c|}{ Statistics for each study } & \multicolumn{2}{|r|}{ Odds ratio and $95 \% \mathrm{Cl}$} & \multirow[b]{2}{*}{$\begin{array}{l}\text { Relative } \\
\text { weight }\end{array}$} \\
\hline & $\begin{array}{c}\text { Odds } \\
\text { ratio }\end{array}$ & $\begin{array}{c}\text { Lower } \\
\text { limit }\end{array}$ & $\begin{array}{l}\text { Upper } \\
\text { limit }\end{array}$ & z-Value & p-Value & & & \\
\hline Diabate ot al & 1.09 & 0.54 & 2.18 & 0.24 & 0.81 & & & 1.23 \\
\hline Cartucci of al & 0.80 & 0.39 & 1.63 & -0.63 & 0.53 & & & 1.15 \\
\hline Fielding ot al & 0.91 & 060 & 1.39 & -0.44 & 0.66 & & & 3.22 \\
\hline Birbeck ot al & 1.07 & 0.49 & 2.33 & 0.16 & 0.87 & & & 0.97 \\
\hline Pirkle et al & 1.00 & 0.53 & 1.88 & -0.01 & 0.99 & & & 1.47 \\
\hline Stubbs et al & 0.90 & 0.46 & 1.74 & -0.32 & 0.75 & & & 1.33 \\
\hline Jaquet et al & 0.78 & 0.52 & 1.17 & -1.20 & 0.23 & & & 3.42 \\
\hline Lester et al & 0.60 & 0.32 & 1.12 & -1.61 & 0.11 & & & 1.50 \\
\hline Watt et al & 0.28 & 0.09 & 0.83 & -2.29 & 0.02 & & & 0.51 \\
\hline Chung et al & 0.59 & 0.27 & 1.30 & -1.31 & 0.19 & & & 0.97 \\
\hline Kunutsor et al & 1.23 & 0.06 & 23.61 & 0.13 & 0.89 & & & 0.07 \\
\hline Messou el al & 0.94 & 0.61 & 1.44 & -0.29 & 0.77 & & & 3.10 \\
\hline Neaca et al & 4.91 & 0.28 & 85.29 & 1.09 & 0.28 & & & 0.07 \\
\hline Mbuagbaw et al & al 1.02 & 0.44 & 2.34 & 0.05 & 0.96 & & & 0.86 \\
\hline Annison et al & 2.10 & 0.61 & 7.19 & 1.18 & 0.24 & & & 0.40 \\
\hline Kiwurwa et al & 0.87 & 0.63 & 1.22 & -0.80 & 0.42 & & - & 4.96 \\
\hline Negash et al & 0.89 & 0.41 & 1.93 & -0.30 & 0.77 & & & 0.99 \\
\hline Jones et al & 0.49 & 0.20 & 1.21 & -1.54 & 0.12 & & $\overline{-1}$ & 0.73 \\
\hline Vinikoor et al & 1.05 & 1.00 & 1.11 & 1.79 & 0.07 & & & 41.77 \\
\hline \multirow[t]{4}{*}{ Muya et al } & 1.11 & 1.01 & 1.21 & 2.25 & 0.02 & & & 31.29 \\
\hline & 1.01 & 0.93 & 1.09 & 0.19 & 0.85 & & & \\
\hline & & & & & & 0.5 & 1 & \\
\hline & & & & & & & Favours Young & \\
\hline
\end{tabular}

Meta Analysis

Fig. 2 Forest plot indicating pooled effect of adherence among older adults compared with younger adults 


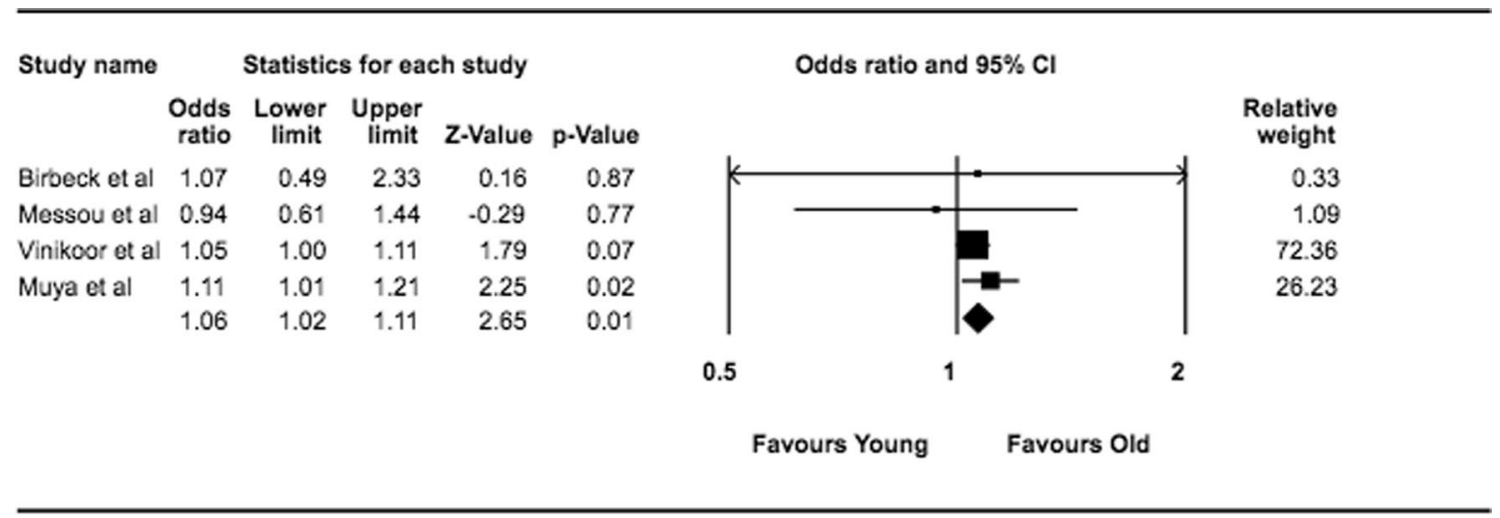

Meta Analysis

Fig. 3 Forest plot indicating sub-group analysis of studies using MPR or clinician contact as adherence measure

significant difference between the two groups OR $0.83(95 \%$ CI 0.63-1.09). The other results for sub-group analysis based on study type were non-significant, cross-sectional studies OR 0.89 (95\% CI 0.69-1.15), prospective cohort studies [OR 0.87 (95\% CI 0.69-1.01)] the analysis of the other study types OR 1.13 (95\% CI 0.68-1.89) see Appendix 3. These results showed that study design was not an important moderator to affect adherence patterns.

The included studies in the analysis had different weights, this weighing is a factor of their sample sizes and variance [36.] However, two studies [38, 39] had a very high relative weight, forming almost $90 \%$ of the pooled results. When these studies were excluded the remaining 18 studies showed younger adults were more likely to be adherent OR 0.85 (95\% CI 0.73-0.98), $\mathrm{p}=0.03$ (Appendix 3).

\section{Discussion}

Our systematic review shows that ART adherence among older people is similar to that of younger people in SSA. Despite a general neglect of programs for older adults living with HIV in Africa and despite issues of poverty, social exclusion, lack of support and mobility challenges, adherence is not statistically different to that of younger people. A 2013 meta-analysis by Ghidei and colleagues identified 12 studies from non-African settings that contained data on older adult adherence compared to younger counterparts [7]. They found that older age reduced the risk of non-adherence by $27 \%$ in the studies from the US, Italy, United Kingdom, Canada and Brazil. Our study found no such difference in their adherence. However, this review included studies that used a variety of different measures of adherence each of which have their own strengths and weaknesses [40]. For example, self-report is a practical tool in low-resource settings, but can overestimate adherence [41]. Pharmacy refill adherence measures such as pill counts and calculation of the medication possession ratio can be impractical and do not measure whether patients are actually taking their medication, although are less prone to reporting bias than selfreport $[42,43]$. Clinical contact measures require a clinician to classify adherence as good or poor, and thus subject to assessment bias and difficult to standardize [43]. All three included measures have been demonstrated to be significantly predictive of detectable viremia [44].

We found that when MPR or clinician counts were used as the measure of adherence, older adults were more adherent than of younger adults. The reasons for this is unclear; however, it could be argued that pharmacy refill-based adherence monitoring tools (e.g. MPR) are better adherence measures than self-report [45]. It is well accepted that there is no gold standard to measure ART adherence [46]. Yet a number of available adherence methods such as self-reports, pill counts, pharmacy records, self-report electronic monitoring, and therapeutic drug levels can be used depending on the setting or the available resources. Self-reports and pharmacy refill are the most common approaches used in Africa due to the low-cost and simplicity. Common limitations include poor sensitivity to detect non-adherence (e.g. social desirability bias for self-report or pill dumping for pill count) but good specificity for pharmacy refills [42]. Therefore, pharmacy refills may accurately capture older persons' adherence behaviour, making it a better measure for this population.

Another interesting finding in our analysis was when two studies with the largest weights were discounted from the pooled analysis, younger adults were significantly more adherent than older adults $\mathrm{p}=0.03$. The key differentiating characteristic of these two studies was that their 'length of follow up' was greater than the other studies i.e. 24 and 60 months respectively. This may mean that longitudinally older adults may be more likely to be adherent to an ART program. Adherence in older adults is complex and the next challenge is to better understand the individual, 
interpersonal, community and structural factors behind adherence, and most importantly, the levers by which adherence could be improved. For example, Shubber and colleagues' in a recent systematic review on patient-reported barriers identified a number of obstacles including depression, stigma and health-service related barriers such as distance from facility [47]. Cultural norms and personal beliefs have been acknowledged as key predictors for medication adherence in elderly [48]. In the indigenous culture illness is sometimes considered as fate, or a condition whose control is held by an external locus $[49,50]$. These believes combined with the likelihood that older adults living in Africa are less likely to be exposed to contemporary western medicine and more likely to have deeper roots in their tradition, when compared to their younger counterparts, makes adherence a challenge. A solution to that can be the inclusion of patient centred pharmaceutical counselling, this may be an important tool to improve their adherence. However, the evidence for effectiveness of pharmaceutical counselling is from developed countries [51, 52], and may not be easily translatable in the context of low-resource countries in Africa. In these settings, the interaction between physical and mental health becomes particularly important [30], and future studies should have a special focus on this aspect.

In developed countries older adults show less attrition on ART [53], and the CD4 reconstitution is low [54-57], thus increasing the importance of early access and strong adherence to reducing mortality. Past studies have explored the impact of depression on adherence in Africa [58] as well as exploring the impact of community-based adherence interventions [59-61]. A number of peer-led interventions, such as medical companions or support groups for people living with HIV, have proven successful in improving ART access and adherence in SSA [62,63] but nearly all exclusively target people under 50 years of age [64]. Therefore, prospective programs need to have a focus on older adults living in low-resource or developing countries.

Understanding reasons for late presentation and mechanisms for addressing that shortcoming would be critical to improving outcomes among older people. Overall, however, there have been very limited HIV-related behavioral interventions among older people [65] which has limited the development of appropriately and specifically targeted programs. In order to achieve global HIV goals, the health providers must strive to improve the quality of care and quality of outcomes among all people living with HIV. While older adults have long been neglected, there are promising signs that their specific needs are now being recognised and that appropriate programs will emerge to ensure that older people remain productive members of their communities.

\section{Limitations}

The diversity of methods used to measure adherence is an inherent challenge in systematic review and meta-analysis as we have undertaken. Further, the lack of standardised conversion of continuous measurements of adherence rates into dichotomous or ordinal data weakens any direct comparison between different adherence levels across studies. Some confounding factors such as chronological age, gender, urban-rural status, overall health, financial status, and mobility could not be accounted for while doing the analysis.

The core challenge in this review was that individual studies varied in their definition and measurement of adherence. To deal with this limitation the authors included an additional variable based sub-analysis, stratified by adherence definition. This sub-grouping and pooling of similar studies may eliminate some confounders for on the variability of methodologies among the studies. Similarly, the authors acknowledge that dichotomising age may have had implications on adherence rates. However, the authors ensured that the age cut-off used are consistent with the WHO definition of older and younger adults in Africa [5]. Another limitation may have been the length of follow-up among the studies, as shorter studies may have a higher adherence rate than longer studies. To understand if there was an effect we ran a linear regression analysis between the length of the studies and adherence rates, and noted that there was no significant difference among the studies due to this variable $(\beta=0.008$, $\mathrm{p}>0.05$ ) (Appendix 4). Despite literature suggesting that adherence changes over time [66], the fact that our analysis data didn't show significance can be attributed to the fact that both older and younger adults maintain similar attrition rates and age is not a contributory factor. This further supports our results that there is no significant difference in among the two age categories.

In the future, studies need to be designed with a standardized measure of adherence in order to improve validity and generalizability. The authors further recommend that studies track adherence data at set time points, for example every three months, this will allow standardized comparison while pooling data for future analysis.

\section{Conclusions}

This systematic review and meta- analysis found ART adherence levels were similar among older and younger adults in Africa. Further research might identify specific barriers to adherence in the HIV affected populations, and targeted interventions to improve clinical outcomes and quality of life when those affected by HIV grow older. 
Funding No funding was received for this study.

\section{Compliance with Ethical Standards}

Conflict of interest All authors declare no conflict of interest.
Open Access This article is distributed under the terms of the Creative Commons Attribution 4.0 International License (http://creativecommons.org/licenses/by/4.0/), which permits unrestricted use, distribution, and reproduction in any medium, provided you give appropriate credit to the original author(s) and the source, provide a link to the Creative Commons license, and indicate if changes were made.

Ethical Approval This article does not contain any studies with human participants or animals performed by any of the authors.

\section{Appendix 1: Quality Assessment Items}

Quality assessment item

Reporting (9 items)

Is hypothesis/aims clearly described?

Are the main outcomes to be measured clearly described?

Are the characteristics of the patients included in the study clearly described

Are the interventions of interest clearly described?

Are the distributions of principal confounders in each group of subjects to be compared clearly described? 2

Are the main findings of the study clearly described?

Does the study provide estimates of the random variability in the data for the main outcomes?

Have all important adverse events that may be a consequence of the intervention been reported?

Have the characteristics of patients lost to follow-up been described?

Have actual probability values been reported (e.g. 0.035 rather than $<0.05$ ) for the main outcomes except where the probability value is less than 0.001 ?

External validity ( 3 items)

Were the subjects asked to participate in the study representative of the entire population from which they were recruited? 1

Were those subjects who were prepared to participate representative of the entire population from which they were 1 recruited?

Were the staff, places, and facilities where the patients were treated, representative of the treatment the majority of patients 1 receive?

Bias (7 items)

If any of the results of the study were based on "data dredging", was this made clear?

In trials and cohort studies, do the analyses adjust for different lengths of follow-up of patients, or in case-control studies, is 1 the time period between the intervention and outcome the same for cases and controls?

Were the statistical tests used to assess the main outcomes appropriate? 1

Was compliance with the intervention/s reliable? 1

Were the main outcome measures used accurate (valid and reliable)?

Confounding (6 items)

Were the patients in different intervention groups (trials and cohort studies) or were the cases and controls (case-control 1 studies) recruited from the same population?

Were study subjects in different intervention groups (trials and cohort studies) or were the cases and controls (case-control 1 studies) recruited over the same period of time?

Were losses of patients to follow-up taken into account?

Power (1 item)

Does the study describe its calculation of power in order to demonstrate a clinically significant effect? 


\section{Appendix 2: Quality Assessment Scores}

\begin{tabular}{llllllll}
\hline Reporting item & $\begin{array}{l}\text { Reporting }(\max \\
11 \text { points) }\end{array}$ & $\begin{array}{l}\text { External valid- } \\
\text { ity (max 3 } \\
\text { points) }\end{array}$ & $\begin{array}{l}\text { Bias }(\max 5 \\
\text { points) }\end{array}$ & $\begin{array}{l}\text { Confounding } \\
(\max 3 \text { points) }\end{array}$ & $\begin{array}{l}\text { Power (max 1 } 1 \\
\text { point) }\end{array}$ & $\begin{array}{l}\text { Total (max 23 } \\
\text { points) }\end{array}$ & Total\% \\
\hline Author & & & & & & & \\
Diabate et al. [67] & 8 & 2 & 4 & 1 & 0 & 15 & 65 \\
Carlucci et al. [68] & 8 & 2 & 5 & 2 & 0 & 15 & 65 \\
Fielding et al. [69] & 10 & 1 & 5 & 3 & 0 & 17 & 74 \\
Birbeck et al. [70] & 8 & 1 & 5 & 3 & 0 & 15 & 65 \\
Pirkle et al. [71] & 7 & 2 & 5 & 2 & 0 & 14 & 61 \\
Stubbs et al. [72] & 11 & 2 & 5 & 2 & 0 & 18 & 78 \\
Jaquet et al. [73] & 8 & 3 & 5 & 0 & 0 & 16 & 70 \\
Lester et al. [74] & 10 & 3 & 5 & 3 & 1 & 20 & 87 \\
Watt et al. [75] & 9 & 1 & 5 & 2 & 0 & 15 & 65 \\
Chung et al. [76] & 10 & 3 & 5 & 3 & 1 & 20 & 87 \\
Kunutsor et al. [77] & 9 & 3 & 4 & 3 & 0 & 17 & 74 \\
Messou et al. [78] & 8 & 2 & 5 & 2 & 0 & 15 & 65 \\
Ncaca et al. [79] & 9 & 3 & 5 & 2 & 0 & 17 & 74 \\
Mbuagbaw et al. [80] & 9 & 2 & 5 & 3 & 1 & 18 & 78 \\
Annison et al. [81] & 7 & 2 & 5 & 2 & 0 & 14 & 61 \\
Kiwuwa-Muyingo et al. & 10 & 2 & 5 & 3 & 0 & 18 & 78 \\
[82] & & & & & & & \\
Negash et al. [83] & 8 & 2 & 5 & 2 & 1 & 16 & 70 \\
Jones et al. [84] & 8 & 2 & 5 & 2 & 0 & 15 & 65 \\
Vinikoor et al. [39] & 8 & 2 & 5 & 3 & 0 & 16 & 70 \\
Muya et al. [38] & 9 & 2 & 5 & 2 & 0 & 16 & 70 \\
\hline
\end{tabular}

\section{Appendix 3: Additional Forest Plots-Sub-Group Analyses}

Analysis of studies using self-report as adherence measure.

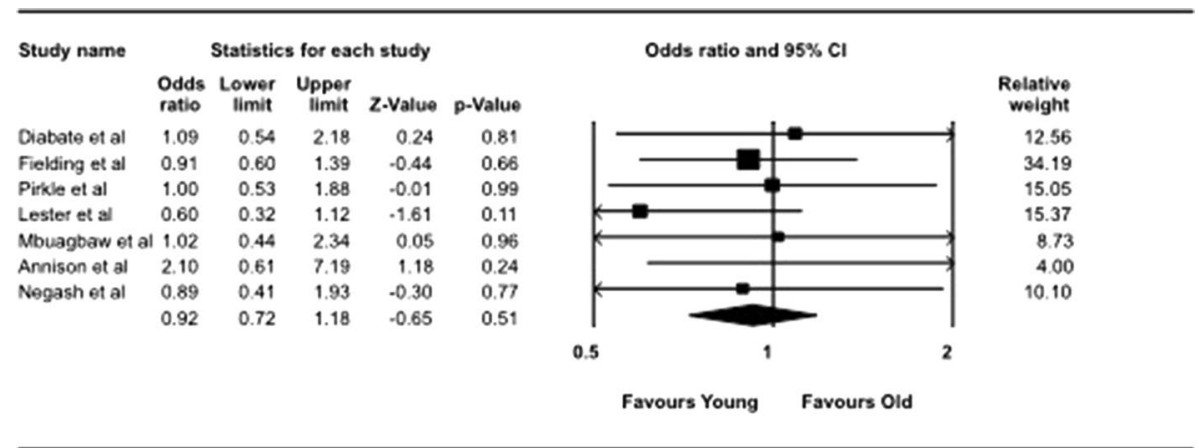

Meta Analysis 
Analysis of studies using pill count as adherence measure.

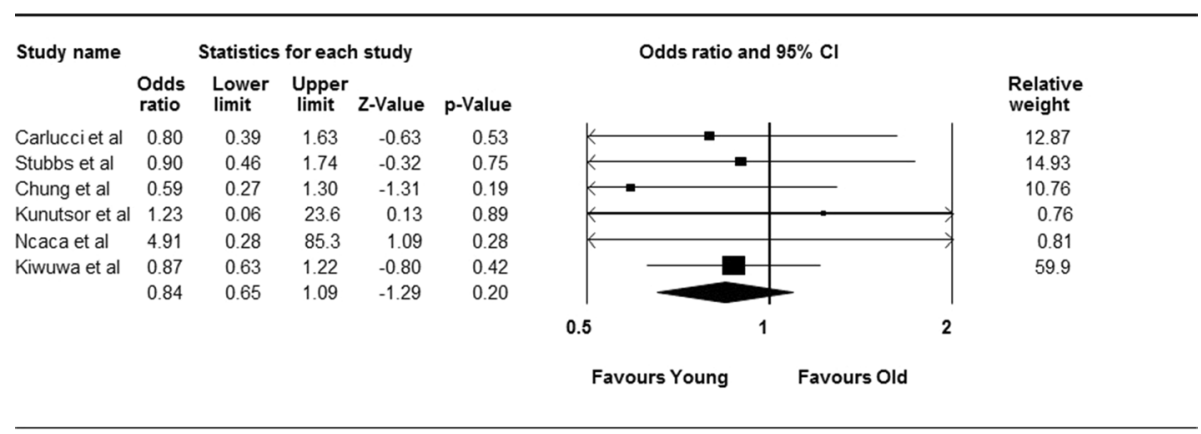

Meta Analysis

Analysis excluding two highest weighted studies.

\begin{tabular}{lcccrr}
\hline Study name & \multicolumn{5}{c}{ Statistics } \\
& $\begin{array}{l}\text { Oddds } \\
\text { ratio }\end{array}$ & $\begin{array}{l}\text { Lower } \\
\text { limit }\end{array}$ & $\begin{array}{l}\text { Upper } \\
\text { limit }\end{array}$ & Z-Value & p-Value \\
Diabete et al & 1.09 & 0.54 & 2.18 & 0.24 & 0.81 \\
Carlucci et al & 0.80 & 0.39 & 1.63 & -0.63 & 0.53 \\
Fielding et al & 0.91 & 0.60 & 1.39 & -0.44 & 0.66 \\
Birbeck et al & 1.05 & 0.48 & 2.29 & 0.11 & 0.91 \\
Pirkle et al & 1.00 & 0.53 & 1.88 & -0.01 & 0.99 \\
Stubbs et al & 0.90 & 0.46 & 1.74 & -0.32 & 0.75 \\
Jaquet et al & 0.78 & 0.52 & 1.17 & -1.20 & 0.23 \\
Lester et al & 0.60 & 0.32 & 1.12 & -1.61 & 0.11 \\
Watt et al & 0.28 & 0.09 & 0.83 & -2.29 & 0.02 \\
Chung et al & 0.59 & 0.27 & 1.30 & -1.31 & 0.19 \\
Kunutsor et al & 0.97 & 0.21 & 4.60 & -0.04 & 0.97 \\
Messou et al & 0.94 & 0.61 & 1.44 & -0.29 & 0.77 \\
Ncaca et al & 4.91 & 0.28 & 85.3 & 1.09 & 0.28 \\
Mbuagbaw et al & 1.02 & 0.44 & 2.34 & 0.05 & 0.96 \\
Annison et al & 2.10 & 0.61 & 7.19 & 1.18 & 0.24 \\
Kiwuwa et al & 0.87 & 0.63 & 1.22 & -0.80 & 0.42 \\
Negash et al & 0.89 & 0.41 & 1.93 & -0.30 & 0.77 \\
Jones et al & 0.49 & 0.20 & 1.21 & -1.54 & 0.12 \\
& 0.85 & 0.73 & 0.98 & -2.19 & 0.03
\end{tabular}

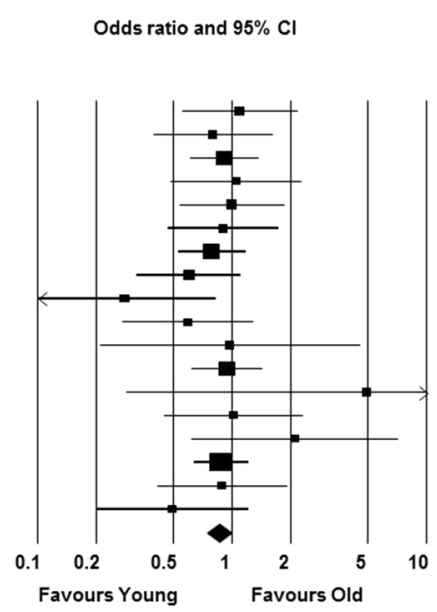

Relative

weight

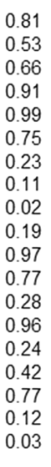

4.41
4.12

\section{Appendix 4: Linear Regression of Study}

Follow-Up Period and Adherence Rates

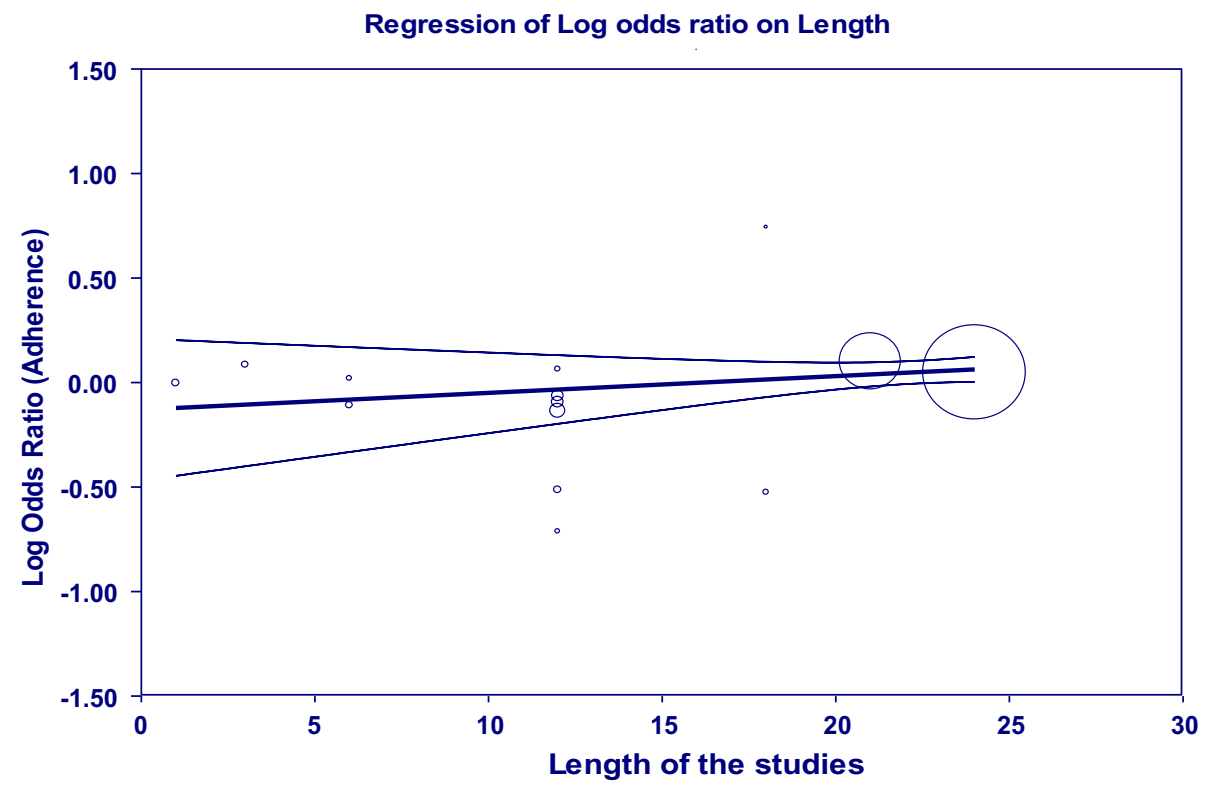




\section{References}

1. UNAIDS. Global HIV statistics, fact sheet. Geneva: UNAIDS; 2017.

2. UNAIDS. Get on the fast-track. The life-cycle approach to HIV. Finding solutions for everyone at every stage of life. Geneva: UNAIDS; 2016.

3. Mahy M, Autenrieth CS, Stanecki K, Wynd S. Increasing trends in HIV prevalence among people aged 50 years and older: evidence from estimates and survey data. AIDS. 2014;28(4):S453.

4. UNAIDS. HIV and aging: a special supplement to the UNAIDS report on the global AIDS epidemic 2013. Geneva: UNAIDS; 2013. p. 2013.

5. WHO. Proposed working definition of an older person in Africa for the MDS project: definition of an older or elderly person. 2002. http://www.who.int/healthinfo/survey/ageingdefnolder/en/.

6. Negin J, Cumming RG. HIV infection in older adults in subSaharan Africa: extrapolating prevalence from existing data. Bull World Health Org. 2010;88(11):847-53.

7. Ghidei L, Simone MJ, Salow MJ, Zimmerman KM, Paquin AM, Skarf LM, et al. Aging, antiretrovirals, and adherence: a meta analysis of adherence among older HIV-infected individuals. Drugs Aging. 2013;30(10):809-19.

8. Freeman E, Anglewicz P. HIV prevalence and sexual behaviour at older ages in rural Malawi. Int J STD AIDS. 2012;23(7):490-6.

9. Negin J, Gregson S, Eaton JW, Schur N, Takaruza A, Mason P, et al. Rising levels of HIV infection in older adults in Eastern Zimbabwe. PLoS ONE. 2016;11(11):e0162967.

10. Cornell M, Johnson LF, Schomaker M, Tanser F, Maskew M, Wood R, et al. Age in antiretroviral therapy programmes in South Africa: a retrospective, multicentre, observational cohort study. Lancet HIV. 2015;2(9):e368-75.

11. Deeks SG, Phillips AN. HIV infection, antiretroviral treatment, ageing, and non-AIDS related morbidity. BMJ (Clinical Research Ed). 2009;338:a3172.

12. Colleen H, Meigs JB, Colleen C, Petra R, Sarah P, Nesli B, et al. Metabolic abnormalities and cardiovascular disease risk factors in adults with human immunodeficiency virus infection and lipodystrophy. Clin Infect Dis. 2001;32(1):130-9.

13. Friis-Møller N, Weber R, Reiss P, Thiébaut R, Kirk O, Monforte AdA, et al. Cardiovascular disease risk factors in HIV patientsassociation with antiretroviral therapy. Results from the DAD study. AIDS. 2003;17(8):1179-93.

14. Granich RM, Gilks CF, Dye C, De Cock KM, Williams BG. Universal voluntary HIV testing with immediate antiretroviral therapy as a strategy for elimination of HIV transmission: a mathematical model. Lancet. 2009;373(9657):48-57.

15. Krumme AA, Kaigamba F, Binagwaho A, Murray MB, Rich ML, Franke MF. Depression, adherence and attrition from care in HIVinfected adults receiving antiretroviral therapy. J Epidemiol Commun Health. 2015;69(3):284-9.

16. Denison JA, Packer C, Stalter RM, Banda H, Mercer S, Nyambe $\mathrm{N}$, et al. Factors related to incomplete adherence to antiretroviral therapy among adolescents attending three HIV clinics in the copperbelt, Zambia. AIDS Behav. 2018;22(3):996-1005.

17. Denison JA, Koole O, Tsui S, Menten J, Torpey K, van Praag E, et al. Incomplete adherence among treatment-experienced adults on antiretroviral therapy in Tanzania, Uganda and Zambia. AIDS. 2015;29(3):361-71.

18. UNAIDS. 90-90-90: an ambitious treatment target to help end the AIDS epidemic. Geneva: UNAIDS; 2014.

19. Negin J, Barnighausen T, Lundgren JD, Mills EJ. Aging with HIV in Africa: the challenges of living longer. AIDS. 2012;26(Suppl 1):S1-5.
20. Abara WE, Adekeye OA, Xu J, Heiman HJ, Rust G. Correlates of combination antiretroviral adherence among recently diagnosed older HIV-infected adults between 50 and 64 years. AIDS Behav. 2016;20(11):2674-81.

21. Johnson CJ, Heckman TG, Hansen NB, Kochman A, Sikkema KJ. Adherence to antiretroviral medication in older adults living with HIV/AIDS: a comparison of alternative models. AIDS Care. 2009;21(5):541-51.

22. Poggenpoel M. Perceived basic needs and resources for the elderly in the peri-urban and rural communities in the Hhohho region in Swaziland. Curationis. 2010.

23. Schatz E, Seeley S, Negin J, Mugisha J, editors. They "don't cure old age": older Ugandans' delays to health care access. American Sociological Association Annual Meeting; 2016; Seattle, WA.

24. High KP, Brennan-Ing M, Clifford DB, Cohen MH, Currier J, Deeks SG, et al. HIV and aging: state of knowledge and areas of critical need for research. A report to the NIH Office of AIDS Research by the HIV and Aging Working Group. J Acquir Immune Defic Syndr. 2012;60(Suppl 1):S1-18.

25. Kuteesa MO, Seeley J, Cumming RG, Negin J. Older people living with HIV in Uganda: understanding their experience and needs. Afr J AIDS Res. 2012;11(4):295-305.

26. Ettenhofer ML, Hinkin CH, Castellon SA, Durvasula R, Ullman $\mathrm{J}$, Lam M, et al. Aging, neurocognition, and medication adherence in HIV infection. Am J Geriatr Psychiatry. 2009;17(4):281-90.

27. Schatz E, Seeley J. Gender, ageing and carework in East and Southern Africa: a review. Glob Public Health. 2015;10(10):1185-200.

28. Mugisha JO, Schatz E, Seeley J, Kowal P. Gender perspectives in care provision and care receipt among older people infected and affected by HIV in Uganda. Afr J AIDS Res. 2015;14(2):159-67.

29. Wright S, Zalwango F, Seeley J, Mugisha J, Scholten F. Despondency among HIV-positive older men and women in Uganda. J Cross Cult Gerontol. 2012;27(4):319-33.

30. Ware NC, Idoko J, Kaaya S, Biraro IA, Wyatt MA, Agbaji O, et al. Explaining adherence success in sub-Saharan Africa: an ethnographic study. PLoS Med. 2009;6(1):e1000011.

31. Heestermans T, Browne JL, Aitken SC, Vervoort SC, KlipsteinGrobusch K. Determinants of adherence to antiretroviral therapy among HIV-positive adults in sub-Saharan Africa: a systematic review. BMJ Glob Health. 2016;1(4):e000125.

32. Sabaté E. Adherence to long-term therapies: evidence for action. Geneva: World Health Organization; 2003.

33. Lassane K, Paul M, Eric C, Anne Z, Greer B, Michael JM. Selfreport measures in the assessment of antiretroviral medication adherence: comparison with medication possession ratio and HIV viral load. J Int Assoc Provid AIDS Care. 2014;14(2):156-62.

34. Chesney MA, Ickovics JR, Chambers DB, Gifford AL, Neidig J, Zwickl B, et al. Self-reported adherence to antiretroviral medications among participants in HIV clinical trials: the AACTG adherence instruments. Patient Care Committee \& Adherence Working Group of the Outcomes Committee of the Adult AIDS Clinical Trials Group (AACTG). AIDS Care. 2000;12(3):255-66.

35. Raebel MA, Schmittdiel J, Karter AJ, Konieczny JL, Steiner JF. Standardizing terminology and definitions of medication adherence and persistence in research employing electronic databases. Med Care. 2013;51(803):S11-21.

36. Brannick MT, Yang L-Q, Cafri G. Comparison of weights for meta-analysis of $r$ and $d$ under realistic conditions. Org Res Methods. 2011;14(4):587-607.

37. Downs SH, Black N. The feasibility of creating a checklist for the assessment of the methodological quality both of randomised and non-randomised studies of health care interventions. J Epidemiol Commun Health. 1998;52(6):377-84.

38. Muya AN, Geldsetzer P, Hertzmark E, Ezeamama AE, Kawawa $\mathrm{H}$, Hawkins $\mathrm{C}$, et al. Predictors of nonadherence to antiretroviral 
therapy among HIV-infected adults in Dar es Salaam, Tanzania. J Int Assoc Provid AIDS Care. 2015;14(2):163-71.

39. Vinikoor MJ, Joseph J, Mwale J, Marx MA, Goma FM, Mulenga LB, et al. Age at antiretroviral therapy initiation predicts immune recovery, death, and loss to follow-up among HIVinfected adults in urban Zambia. AIDS Res Human Retrovir. 2014;30(10):949-55.

40. Farmer KC. Methods for measuring and monitoring medication regimen adherence in clinical trials and clinical practice. Clin Ther. 1999;21(6):1074-90.

41. Godin G, Gagne C, Naccache H. Validation of a self-reported questionnaire assessing adherence to antiretroviral medication. 2003 Jul. Report No.: 1087-2914 (Print) 1087-2914 Contract No.: 7.

42. Steiner JF, Prochazka AV. The assessment of refill compliance using pharmacy records: methods, validity, and applications. J Clin Epidemiol. 1997;50:105-16.

43. Fairley CK, Permana A, Read TRH. Long-term utility of measuring adherence by self-report compared with pharmacy record in a routine clinic setting. HIV Med. 2005;6:366-9.

44. Chalker JC, Andualem T, Gitau LN, Ntaganira J, Obua C, Tadeg $\mathrm{H}$, et al. Measuring adherence to antiretroviral treatment in resource-poor settings: the feasibility of collecting routine data for key indicators. BMC Health Serv Res. 2010;10:43.

45. Mekuria LA, Prins JM, Yalew AW, Sprangers MAG, Nieuwkerk PT. Which adherence measure-self-report, clinician recorded or pharmacy refill - is best able to predict detectable viral load in a public ART programme without routine plasma viral load monitoring? Trop Med Int Health. 2016;21(7):856-69.

46. McMahon JH, Manoharan A, Wanke CA, Mammen S, Jose H, Malini T, et al. Pharmacy and self-report adherence measures to predict virological outcomes for patients on free antiretroviral therapy in Tamil Nadu, India. AIDS Behav. 2013;17(6):2253-9.

47. Chesney MA. The elusive gold standard. Future perspectives for HIV adherence assessment and intervention. J Acquir Immune Defic Syndr. 2006;43(Suppl 1):S149-55.

48. Shubber Z, Mills EJ, Nachega JB, Vreeman R, Freitas M, Bock $\mathrm{P}$, et al. Patient-reported barriers to adherence to antiretroviral therapy: a systematic review and meta-analysis. PLoS Med. 2016;13(11):e1002183.

49. Balkrishnan R. Predictors of medication adherence in the elderly. Clin Ther. 1998;20(4):764-71.

50. Horne M, Tierney S. What are the barriers and facilitators to exercise and physical activity uptake and adherence among South Asian older adults: a systematic review of qualitative studies. Prev Med. 2012;55(4):276-84.

51. Al-Rashed S, Wright D, Roebuck N, Sunter W, Chrystyn H. The value of inpatient pharmaceutical counselling to elderly patients prior to discharge. Br J Clin Pharmacol. 2002;54(6):657-64.

52. George J, Elliott RA, Stewart DC. A systematic review of interventions to improve medication taking in elderly patients prescribed multiple medications. Drugs Aging. 2008;25(4):307-24.

53. Darr A, Astin F, Atkin K. Causal attributions, lifestyle change, and coronary heart disease: illness beliefs of patients of South Asian and European origin living in the United Kingdom. Heart Lung: J Acute Crit Care. 2008;37(2):91-104.

54. Nachega JB, Hsu AJ, Uthman OA, Spinewine A, Pham PA. Antiretroviral therapy adherence and drug-drug interactions in the aging HIV population. AIDS. 2012;26:S39-53.

55. Eduardo E, Lamb MR, Kandula S, Howard A, Mugisha V, Kimanga D, et al. Characteristics and Outcomes among older HIV-positive adults enrolled in HIV programs in four Sub-Saharan African Countries. PLoS ONE. 2014;9(7):e103864.

56. Mutevedzi PC, Lessells RJ, Rodger AJ, Newell M-L. Association of age with mortality and virological and immunological response to antiretroviral therapy in rural South African adults. PLoS ONE. 2011;6(7):e21795.

57. Fatti G, Mothibi E, Meintjes G, Grimwood A. Antiretroviral treatment outcomes amongst older adults in a large multicentre cohort in South Africa. PLoS ONE. 2014;9(6):e100273.

58. Negin J, van Lettow M, Semba M, Martiniuk A, Chan A, Cumming RG. Anti-retroviral treatment outcomes among older adults in Zomba district, Malawi. PLoS ONE. 2011;6(10):e26546.

59. Nakimuli-Mpungu E, Bass JK, Alexandre P, Mills EJ, Musisi S, Ram M, et al. Depression, alcohol use and adherence to antiretroviral therapy in sub-Saharan Africa: a systematic review. AIDS Behav. 2012;16(8):2101-18.

60. Haberer JE, Sabin L, Amico KR, Orrell C, Galarraga O, Tsai $\mathrm{AC}$, et al. Improving antiretroviral therapy adherence in resourcelimited settings at scale: a discussion of interventions and recommendations. J Int AIDS Soc. 2017;20(1):1-15.

61. Nachega JB, Adetokunboh O, Uthman OA, Knowlton AW, Altice FL, Schechter M, et al. Community-based interventions to improve and sustain antiretroviral therapy adherence, retention in HIV care and clinical outcomes in low- and middle-income countries for achieving the UNAIDS 90-90-90 targets. Curr HIV/ AIDS Rep. 2016;13(5):241-55.

62. Mills EJ, Lester R, Thorlund K, Lorenzi M, Muldoon K, Kanters $\mathrm{S}$, et al. Interventions to promote adherence to antiretroviral therapy in Africa: a network meta-analysis. Lancet HIV. 2014;1(3):e104-11.

63. Mathes T, Antoine S-L, Pieper D. Adherence-enhancing interventions for active antiretroviral therapy in sub-Saharan Africa: a systematic review and meta-analysis. Sex Health. 2014;11(3):230-9.

64. Wouters E, Masquillier C, Ponnet K, le Roux Booysen F. A peer adherence support intervention to improve the antiretroviral treatment outcomes of HIV patients in South Africa: the moderating role of family dynamics. Soc Sci Med. 2014;113:145-53.

65. Negin J, Rozea A, Martiniuk AL. HIV behavioural interventions targeted towards older adults: a systematic review. BMC Public Health. 2014;14(1):1.

66. Negin J, Rozea A, Martiniuk AL. HIV behavioural interventions targeted towards older adults: a systematic review. BMC Public Health. 2014;14:507.

67. Diabate S, Alary M, Koffi CK. Determinants of adherence to highly active antiretroviral therapy among HIV-1-infected patients in Cote d'Ivoire. AIDS. 2007;21(13):1799-803.

68. Carlucci JG, Kamanga A, Sheneberger R, Shepherd BE, Jenkins CA, Spurrier J, et al. Predictors of adherence to antiretroviral therapy in rural Zambia. J Acquir Immune Defic Syndr. 2008;47(5):615-22.

69. Fielding KL, Charalambous S, Stenson AL, Pemba LF, Martin DJ, Wood R, et al. Risk factors for poor virological outcome at 12 months in a workplace-based antiretroviral therapy programme in South Africa: a cohort study. BMC Infect Dis. 2008;8:93.

70. Birbeck GL, Chomba E, Kvalsund M, Bradbury R, Mang'ombe $\mathrm{C}$, Malama K, et al. Antiretroviral adherence in rural Zambia: the first year of treatment availability. Am J Trop Med Hyg. 2009;80(4):669-74.

71. Pirkle CM, Boileau C, Nguyen VK, Machouf N, Ag-Aboubacrine $\mathrm{S}$, Niamba PA, et al. Impact of a modified directly administered antiretroviral treatment intervention on virological outcome in HIV-infected patients treated in Burkina Faso and Mali. HIV Med. 2009;10(3):152-6.

72. Stubbs BA, Micek MA, Pfeiffer JT, Montoya P, Gloyd S. Treatment partners and adherence to HAART in Central Mozambique. AIDS Care. 2009;21(11):1412-9.

73. Jaquet A, Ekouevi DK, Bashi J, Aboubakrine M, Messou E, Maiga M, et al. Alcohol use and non-adherence to antiretroviral therapy in HIV-infected patients in West Africa. Addiction. 2010;105(8):1416-21. 
74. Lester RT, Ritvo P, Mills EJ, Kariri A, Karanja S, Chung MH, et al. Effects of a mobile phone short message service on antiretroviral treatment adherence in Kenya (WelTel Kenya1): a randomised trial. Lancet. 2010;376(9755):1838-45.

75. Watt MH, Maman S, Golin CE, Earp JA, Eng E, Bangdiwala SI, et al. Factors associated with self-reported adherence to antiretroviral therapy in a Tanzanian setting. AIDS Care. 2010;22(3):381-9.

76. Chung MH, Richardson BA, Tapia K, Benki-Nugent S, Kiarie JN, Simoni JM, et al. A randomized controlled trial comparing the effects of counseling and alarm device on HAART adherence and virologic outcomes. PLoS Med. 2011;8(3):e1000422.

77. Kunutsor S, Walley J, Katabira E, Muchuro S, Balidawa H, Namagala E, et al. Improving clinic attendance and adherence to antiretroviral therapy through a treatment supporter intervention in Uganda: a randomized controlled trial. AIDS Behav. 2011;15(8):1795-802.

78. Messou E, Chaix ML, Gabillard D, Minga A, Losina E, Yapo V, et al. Association between medication possession ratio, virologic failure and drug resistance in HIV-1-infected adults on antiretroviral therapy in Cote d'Ivoire. J Acquir Immune Defic Syndr. 2011;56(4):356-64.

79. Ncaca LN, Kranzer K, Orrell C. Treatment interruption and variation in tablet taking behaviour result in viral failure: a case-control study from Cape Town, South Africa. PLoS ONE. 2011;6(8):e23088.

80. Mbuagbaw L, Thabane L, Ongolo-Zogo P, Lester RT, Mills EJ, Smieja M, et al. The Cameroon Mobile Phone SMS (CAMPS) trial: a randomized trial of text messaging versus usual care for adherence to antiretroviral therapy. PLOS ONE. 2012;7(12):e46909.

81. Annison L, Dompreh A, Adu-Sarkodie Y. The immunological response of HIV-positive patients initiating HAART at the Komfo Anokye Teaching Hospital, Kumasi, Ghana. Ghana Med J. 2013;47(4):164-70.

82. Kiwuwa-Muyingo S, Oja H, Walker A, Ilmonen P, Levin J, Mambule, et al. Dynamic logistic regression model and population attributable fraction to investigate the association between adherence, missed visits and mortality: a study of HIV-infected adults surviving the first year of ART. BMC Infect Dis. 2013;13:395.

83. Negash T, Ehlers V. Personal factors influencing patients' adherence to ART in Addis Ababa, Ethiopia. J Assoc Nurses in AIDS Care. 2013;24(6):530-8.

84. Jones D, Cook R, Spence A, Weiss SM, Chitalu N. Antiretroviral therapy in Zambia: do partners on ART enhance adherence? J Int Assoc Provid AIDS Care. 2014;13(6):497-500. 